\title{
Correction to: Matrine attenuates endoplasmic reticulum stress and mitochondrion dysfunction in nonalcoholic fatty liver disease by regulating SERCA pathway
}

Xiaobo Gao ${ }^{\dagger}$, Shun Guo ${ }^{\dagger}$, Song Zhang ${ }^{\dagger}$, An Liu, Lei Shi ${ }^{*}$ and Yan Zhang*

\section{Correction to: J Transl Med (2018) 16:319}

https://doi.org/10.1186/s12967-018-1685-2

Following publication of the original article [1], the authors reported errors in Fig. 5. The ROS picture of low dose Marine intervention group in Fig. 5d was used incorrectly, which was caused by the error of the storage path of the picture in the experiment. It was not discovered in time due to the approximation of the two graphs. In addition, the label of middle dose Marine intervention group in Fig. 5a was omitted.

In this Correction the incorrect and corrected version of Fig. 5 are shown. 
Originally Fig. 5 was published as:
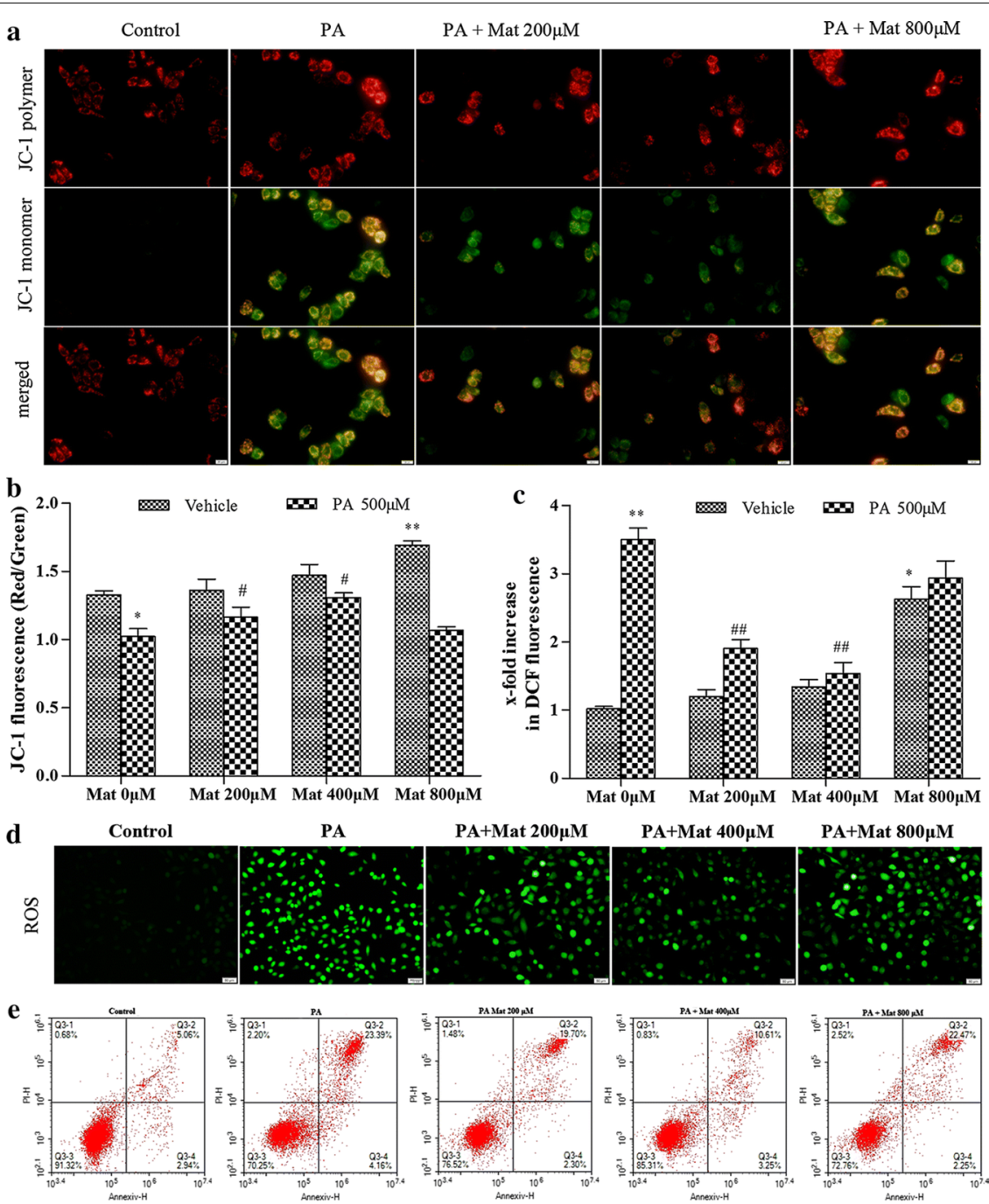

$\mathbf{f}$
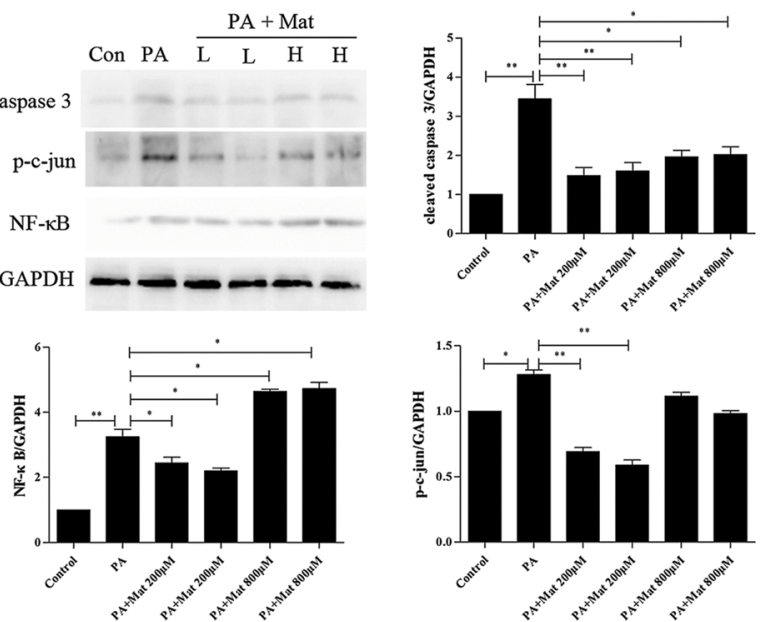

Fig. 5 Effect of Mat on mitochondrial activation, ROS production and apoptosis in PA-induced L02 cells. The L02 cells were treated with PA $(500 \mu \mathrm{M})$, Mat $(200,400,800 \mu \mathrm{M})$ or the combination of PA $(500 \mu \mathrm{M})$ and Mat $(200,400,800 \mu \mathrm{M})$ for $12 \mathrm{~h}$. a Mitochondrial membrane potential $(\mathrm{MMP})$ imaging $(\times 400)$. b JC-1 fluorescence and $\mathbf{c ~ D C F}$ fluorescence detected by fluorescence spectrophotometer. ${ }^{*} \mathrm{P}<0.05$ and ${ }^{* *} \mathrm{P}<0.01 \mathrm{vs}$. Control, ${ }^{\#} P<0.05$ and ${ }^{\#} P<0.01$ vs. PA. $\mathbf{d}$ ROS imaging $(\times 400)$. e apoptosis analyzed by flow cytometry. $\mathbf{f}$ Expression of cleaved caspase $3, p-c-j u n$ and NF-KB in L02 cells. ${ }^{*} \mathrm{P}<0.05$ and ${ }^{* *} \mathrm{P}<0.01$ 
The corrected version of Fig. 5:

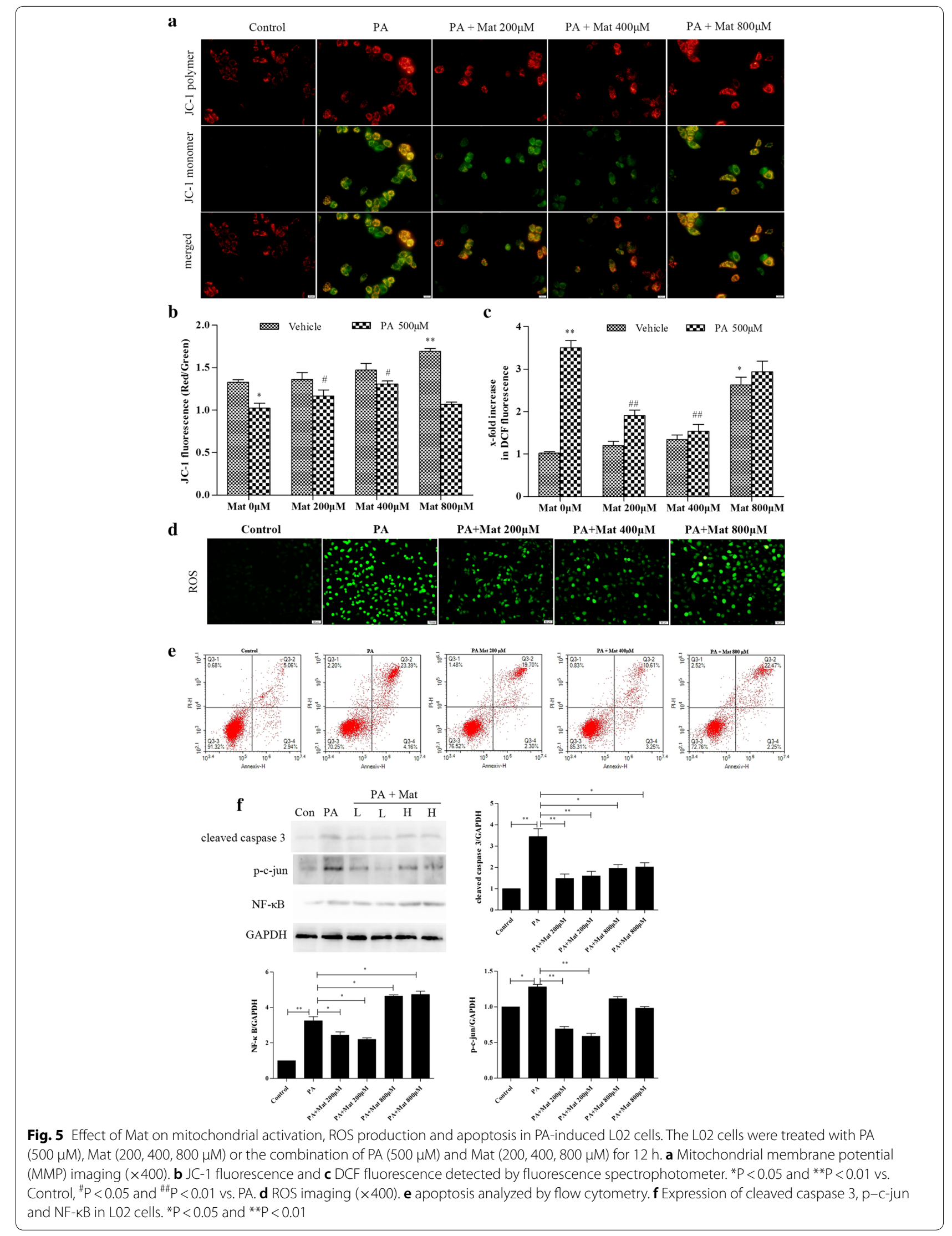


The original article can be found online at https://doi.org/10.1186/s1296 7-018-1685-2

\section{Publisher's Note}

Springer Nature remains neutral with regard to jurisdictional claims in published maps and institutional affiliations.

Published online: 21 August 2019

\section{Reference}

1. Gao X, Guo S, Zhang S, Liu A, Shi L, Zhang Y. Matrine attenuates endoplasmic reticulum stress and mitochondrion dysfunction in nonalcoholic fatty liver disease by regulating SERCA pathway. J Transl Med. 2018;16:319. https://doi.org/10.1186/s12967-018-1685-2. 